\title{
Measurement of thermal expansion at low temperatures using the strain gage method
}

\author{
Ke TANG ${ }^{\dagger}$, Long SHA, Yi-jian LI, Tao JIN ${ }^{\dagger !}$, Shu-juan LIU \\ (Institute of Refrigeration and Cryogenics, Zhejiang University, Hangzhou 310027, China) \\ †E-mail: ktang@zju.edu.cn; jintao@zju.edu.cn \\ Received Feb. 13, 2014; Revision accepted Mar. 27, 2014; Crosschecked Apr. 22, 2014
}

\begin{abstract}
Accurate thermal expansion data of material at low temperatures are important in material selection and structural design for a cryogenic system. In this study, an experimental setup with a proportional-integral-derivative (PID) temperature control system was developed to measure the thermal expansion of solid materials at low temperatures (77-293 K), using the strain gage method. To avoid the impact of the varied sensitivity coefficient of the strain gage with the temperature to ensure an accurate measurement, we corrected the sensitivity coefficient in the temperature range of 77-293 K, by comparing the measured thermal expansion data for 304 stainless steel with the source data from the National Institute of Standards and Technology, USA. With the corrected sensitivity coefficient of the strain gage, the measured linear contractions of oxygen-free copper become quite consistent with the NIST data (with a relative deviation of $2.37 \%$ ) for the cooling-down process from $293 \mathrm{~K}$ to $80 \mathrm{~K}$.
\end{abstract}

Key words: Thermal expansion, Linear contraction, Strain gage method, Cryogenic temperature doi: 10.1631 jzus.A1400051

Document code: A

CLC number: TB302

\section{Introduction}

Cryogenic technology has been widely used in the aerospace industry, air separation industry, natural gas industry, and large scientific apparatus, etc. The selection of material and the structural design of cryogenic systems are very important and attract a great deal of attention. Thermal expansion is one of the key thermophysical properties of cryogenic engineering materials, since there is a significant temperature difference between its operating and manufacturing status. Accurate measurement of thermal expansion at low temperatures is necessary to ensure the security and reliability of the cryogenic systems.

The methods to measure the thermal expansion of solid material can be classified, according to an extensometer, into quartz dilatometer, interferometer, optical lever, mechanical lever, strain gages, magnetic meter, pointer meter, and capacitance microm-

\footnotetext{
¿ Corresponding author

(C) Zhejiang University and Springer-Verlag Berlin Heidelberg 2014
}

eter methods, etc. The quartz dilatometer method is frequently used at low temperatures, because of its high accuracy (Clark, 1968; James et al., 2001; Deng and $\mathrm{Xu}, 2003$; Tezvergil et al., 2003). However, it is expensive and complicated to operate, and is quite demanding on the test specimen dimensions. For a test specimen of large length, the accuracy may be affected by the potential temperature gradient along it, which then requires a cryostat to have high temperature uniformity.

The strain gage method is also commonly used to measure the thermal expansion of material at low temperatures. The thermal strain caused by temperature variation can be measured by a strain gage to reflect the linear thermal expansion features (Poore and Kesterson, 1978; Valentich, 1985; Walsh and Reed, 1994). Compared with the quartz dilatometer method, the strain gage method has lower requirements in the machining accuracy of the test specimen, and the impact of the non-uniform temperature field is also effectively reduced, leading to a lower operational cost. However, most existing systems control 
the measuring temperature by adjusting the altitude of the test specimen in the cryogenic containers (Kaufman, 1963), which may induce much error in temperature control and measurement. In addition, the strain gage sensitivity coefficient may vary due to low temperatures, thus the correction of the strain gage sensitivity coefficient at low temperatures must also be considered for an accurate measurement.

Based on previous studies (Poore and Kesterson, 1978; Valentich 1985; Walsh and Reed, 1994), an experimental setup based on the strain gage method with a proportional-integral-derivative (PID) temperature control system was developed to measure the thermal expansion of solid material at low temperatures. The temperature control system has two operating modes, i.e., stepping mode and constant rate mode. The two temperature control modes were introduced and compared, and the constant rate mode was adopted in our present measurement study. Since the variation of the sensitivity coefficient of strain gages at low temperatures is a key factor affecting the accurate measurement, it was corrected in the temperature range of 77-293 K, by comparing the measured thermal expansion data of 304 stainless steel with the source data from National Institute of Standards and Technology (NIST), USA. To verify the test apparatus and methodology, the measured linear contractions of oxygen-free copper with the corrected sensitivity coefficient of strain gages are also compared with the NIST data.

\section{Strain gage method}

The characteristic parameters of thermal expansion mainly include the linear contraction, the mean linear coefficient of thermal expansion, and the instantaneous linear coefficient of thermal expansion. When the temperature decreases from $293 \mathrm{~K}$ to $T$ $(\Delta T=293-T)$, the linear contraction is defined as the relative variation of the unit length caused by the temperature variation, i.e., $\Delta L / L_{0}$, where $\Delta L$ is the length variation and $L_{0}$ is the original length at $293 \mathrm{~K}$. The mean linear coefficient of thermal expansion of the test specimen is defined as the relative variation of the unit length per Kelvin from $293 \mathrm{~K}$ to $T$, expressed as $\alpha=\left(\Delta L / L_{0}\right)(1 / \Delta T)$, and the instantaneous linear coefficient of thermal expansion is defined as the linear thermal expansion per Kelvin at $T$, expressed as $\alpha_{\mathrm{L}}=\left(1 / L_{0}\right)(\mathrm{d} L / \mathrm{d} T)$. In a Cartesian coordinate system with the temperature as horizontal axis and the contraction as vertical axis, the slope value of the line from the initial point $(293 \mathrm{~K})$ to any point on the contraction-temperature curve is exactly the mean linear coefficient of thermal expansion, while the slope value of the tangent line at that point is the instantaneous linear coefficient of thermal expansion at that temperature. Since the mean linear coefficient and the instantaneous linear coefficient of thermal expansion can be achieved from the linear contraction, the discussion in the section on the test results will focus on the linear contraction.

A strain gage can measure the thermal strain on the surface of a test specimen to reflect the linear contraction of material, and the strain can be transformed into the electric signal with a high precision (Hannah and Reed, 1992). The strain caused by temperature variation is defined as thermal output (Scalea, 1998; Yasmin and Daniel, 2004). Without a mechanical force imposed on the test specimen, the temperature variation can lead to a length variation both in the test specimen and in the strain gage, which then induces the resistivity variation of the strain gage. The resistance variation caused by the two mechanisms can be expressed as

$$
\Delta R / R=\phi_{\mathrm{s}} \Delta T+K_{\mathrm{s}}\left(\alpha-\alpha_{\mathrm{s}}\right) \Delta T,
$$

where $R$ is the resistance of strain gage, $\Delta R$ is the resistance variation quantity of strain gage, $K_{\mathrm{s}}$ is the sensitivity coefficient of strain gage, $\phi_{\mathrm{s}}$ is the temperature coefficient of resistance of the strain gage, and $\alpha_{\mathrm{s}}$ is the mean linear coefficient of thermal expansion of the strain gage. The thermal output can be expressed as

$$
\varepsilon_{\mathrm{t}}=\frac{1}{K_{\mathrm{s}}} \frac{\Delta R}{R}=\frac{\phi_{\mathrm{s}} \Delta T}{K_{\mathrm{s}}}+\left(\alpha-\alpha_{\mathrm{s}}\right) \Delta T
$$

Note that $K_{\mathrm{s}}, \phi_{\mathrm{s}}$, and $\alpha_{\mathrm{s}}$ are all temperaturedependent variables. To eliminate the influence of $\phi_{\mathrm{s}}$ and $\alpha_{\mathrm{s}}$ due to temperature variation, two identical strain gages were mounted onto two pieces (test 
specimen and reference piece) in the same temperature surroundings, and then connected into a half-bridge circuit as shown in Fig. 1. $U_{0}$ is the excitation voltage, $\Delta U$ is the output voltage, $R_{1}$ is the resistance of the strain gage on the test specimen, $R_{2}$ is the resistance of the compensated strain gage on the reference piece, and $R_{3}$ and $R_{4}$ are the standard resistances.

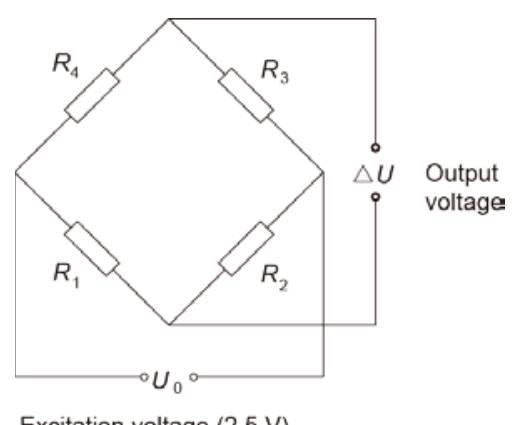

Fig. 1 Schematic of the half-bridge circuit for a strain gage measurement

When the temperature varies, the thermal outputs of the two strain gages $\varepsilon_{\mathrm{t} 1}$ and $\varepsilon_{\mathrm{t} 2}$ are

$$
\varepsilon_{\mathrm{t} 1}=\frac{\phi_{\mathrm{s}} \Delta T}{K_{\mathrm{s}}}+\left(\alpha_{1}-\alpha_{\mathrm{s}}\right) \Delta T
$$

and

$$
\varepsilon_{\mathrm{t} 2}=\frac{\phi_{\mathrm{s}} \Delta T}{K_{\mathrm{s}}}+\left(\alpha_{2}-\alpha_{\mathrm{s}}\right) \Delta T
$$

where $\alpha_{1}$ and $\alpha_{2}$ are the mean linear coefficients of thermal expansion of the test specimen and the reference piece, respectively. According to the half-bridge principle, the acquired signal is the difference between these two thermal outputs, $\Delta \varepsilon_{\mathrm{t}}=\varepsilon_{\mathrm{t} 1}-\varepsilon_{\mathrm{t} 2}=\left(\alpha_{1}-\alpha_{2}\right) \Delta T$. The relationship between the mean linear coefficient of the thermal expansion of the two pieces and their thermal outputs can be written as

$$
\alpha_{1}=\Delta \varepsilon_{\mathrm{t}} / \Delta T+\alpha_{2}
$$

Therefore, the linear contraction of the test specimen can be expressed as

$$
\Delta L / L_{0}=\Delta \varepsilon_{\mathrm{t}}+\alpha_{2} \Delta T
$$

Thus, the linear contraction of the test specimen can be obtained with the measured $\Delta \varepsilon_{\mathrm{t}}$ and $\Delta T$, as well as the mean linear coefficient of thermal expansion of the reference piece $\alpha_{2}$. Since the fused silica glass of high purity $(>99.99 \%)$ has a tiny and almost temperature-independent mean linear coefficient of thermal expansion $\left(5.5 \times 10^{-7} \mathrm{~K}^{-1}\right)$ (Poore and Kesterson, 1978), it is frequently used as the reference piece in the measurement of thermal expansion.

\section{Experimental setup}

The experimental setup to measure the thermal expansion of material at low temperatures is shown in Fig. 2, which consists of a liquid nitrogen container, a test cavity, a PID temperature regulator, a constant voltage DC source, a computer, and a data acquisition system.

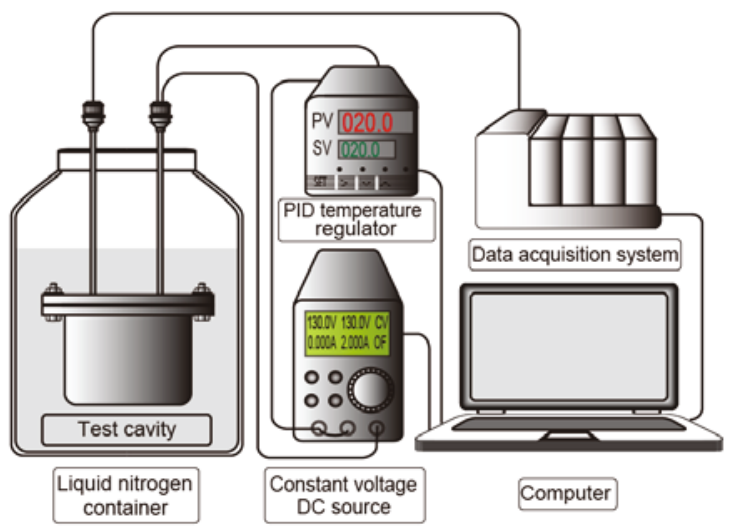

Fig. 2 Schematic of measurement system for thermal expansion of solid materials at low temperatures

The test cavity, as presented in Fig. 3, is mainly composed of a stainless steel chamber, thermal insulating material, a heating band, a copper cavity, a polytetrafluoroethene (PTFE) tray, a test specimen, a reference piece, and a temperature measuring block. The whole stainless steel chamber is emerged into liquid nitrogen to cool the test specimen. The heating flux supplied by the heating band can be adjusted by the PID temperature regulator to balance the heat leakage to the liquid nitrogen, resulting in a stable operation at any preset test temperature in the range of $77-293 \mathrm{~K}$. The dimensions of the test specimen are $12 \mathrm{~mm} \times 12 \mathrm{~mm} \times 4 \mathrm{~mm}$. Its relatively small dimensions can reduce the difficulty in machining and the 
influence of the non-uniform temperature field on the measurement accuracy. The reference piece with the same dimensions is made from fused silica glass of 99.99\% purity. The temperature measuring block (the same material as the test specimen) also has the same dimensions, while it was drilled with holes for inserting thermometers.

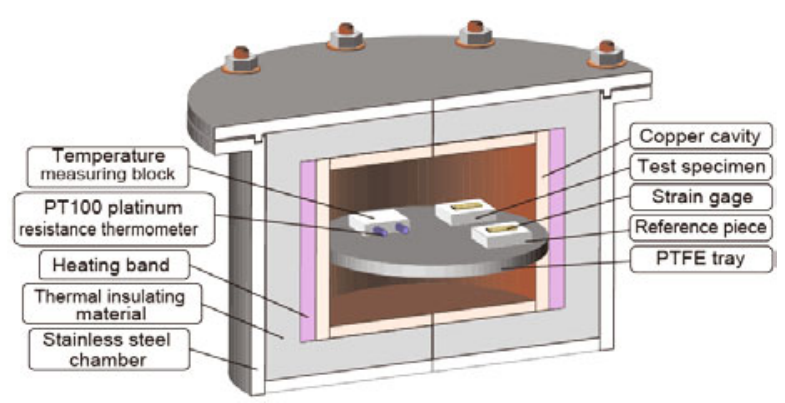

Fig. 3 Schematic of the test cavity

Two identical strain gages were mounted at the center of the test specimen surface and the reference piece surface to measure the linear contraction. The gages were then connected into a half-bridge circuit as shown in Fig. 1. The Ni-Cr resistive elements BB120-4AA250 (11) Karma foil strain gages (Zhonghang Electronic Measuring Instruments Co. Ltd., China) were used. The design operating temperature of the strain gages is $4-523 \mathrm{~K}$, the nominal resistance is (119.6 \pm 0.1$) \Omega$, and the nominal sensitivity coefficient is $1.76 \pm 0.01$. The strain signal is acquired by an NI9237 DAQ module (National Instruments, USA), which has an internal excitation source of 2.5-10 V. In addition, the NI9237 DAQ module measures the load voltage instead of the internal excitation source voltage to eliminate the error caused by wire resistance, while the shunt calibration can eliminate the error caused by the digital to analogue converter (DAC).

A PT100 platinum resistance thermometer with an accuracy of $\pm 0.1 \mathrm{~K}$, combined with an NI9217 RTD analog input module, was used for the temperature measurement. The thermometer was inserted into the temperature measuring block, which was placed at a symmetric location to the test specimen.

The test temperature control needs a cooperation of the constant voltage DC source, the heater band, the PT100 platinum resistance thermometer, the PID temperature regulator, and the computer. The PID temperature regulator and constant voltage source are connected to the computer through an RS-485 asynchronous serial communication interface. According to the standard of ASTM E228-2006, the temperature can be adjusted in steps or by a slow constant rate. The temperature control system in our apparatus can achieve both operating modes. In the stepping mode, the PID temperature regulator controls the temperature by the preset $\mathrm{P}, \mathrm{I}$, and $\mathrm{D}$ control parameters, which can be calculated from the aforehand self-tuning experiments. Due to the large temperature range of 77-293 K, a single set of $\mathrm{P}$, I, and D control parameters cannot adequately satisfy the requirements of an accurate control (a fluctuation within $\pm 0.1 \mathrm{~K}$ ). Therefore, several groups of parameters should be obtained by dividing the wide temperature range into relatively narrow ones. In the constant rate mode, a program based on LabVIEW software was developed to control the on/off switch timing of the relay in the temperature regulator, resulting in a relatively constant cooling-down rate for the test specimen.

\section{Test results and discussion}

\subsection{Comparison of two temperature control modes}

Fig. 4 presents the temperature evolution of the case controlled by the stepping mode. With the sets of $\mathrm{P}, \mathrm{I}$, and D parameters achieved from the self-tuning experiments for each $40 \mathrm{~K}$ temperature range, the system can be kept at diverse target temperatures with a fluctuation below $\pm 0.1 \mathrm{~K}$. A couple of hours are required to reach the stable status for each target temperature. Although the stepping mode is advantageous for accurate control of the target temperature, the long measurement time hinders its application for the measurements with variable target temperatures.

According to ASTM E228-2006, the constant rate mode is available for the temperature control in the measurement of linear thermal expansion. The key point is that the temperature variation rate should be low enough to sufficiently depress the temperature's non-uniformity, thereby ensuring the temperature measurement accuracy. The space between the stainless steel cavity and copper cavity was filled with thermal insulating material, combined with the 
heating band, to slow down the temperature varying rate, e.g., $0.3 \mathrm{~K} / \mathrm{min}$ as shown in Fig. 5. To validate the rationality of the constant rate mode with $0.3 \mathrm{~K} / \mathrm{min}$, we compared the data for linear contractions of 304 stainless steel achieved from the constant rate mode and the stepping mode, as shown in Fig. 6. Note that there is no significant difference of the linear contractions (less than $0.26 \%$ at each target temperature) between the two modes, which indicates that the constant rate mode with $0.3 \mathrm{~K} / \mathrm{min}$ is acceptable. Comparing Figs. 4 and 5, the constant rate mode takes $14 \mathrm{~h}$ to accomplish a relatively quick measurement. In addition, the mean rate is $0.3 \mathrm{~K} / \mathrm{min}$ before reaching $83 \mathrm{~K}(12 \mathrm{~h})$, and then becomes much lower because of the small temperature difference between the test specimen and the surroundings.

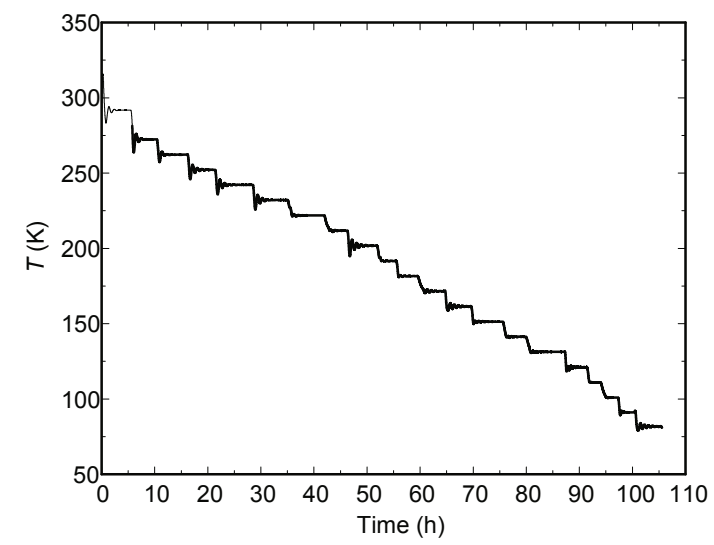

Fig. 4 Controlled temperature for stepping mode

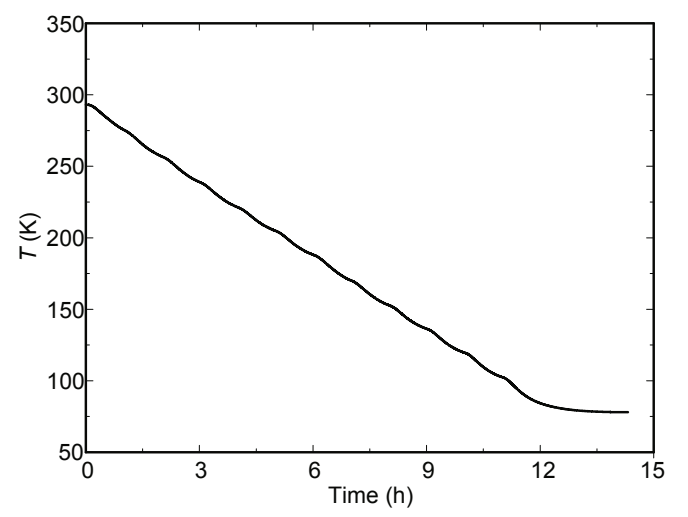

Fig. 5 Controlled temperature for constant rate mode

Based on the above comparison, the constant rate mode with $0.3 \mathrm{~K} / \mathrm{min}$ was adopted in our measurements. Assembled as in Fig. 3, the cavity was emerged into the liquid nitrogen. After the shunt calibration and zero setting for $293 \mathrm{~K}$ in the stepping mode, the temperature control system was then switched to the constant rate mode. Then, the variation of the linear contraction along with the temperature was acquired by the computer-based measurement and calculation application.

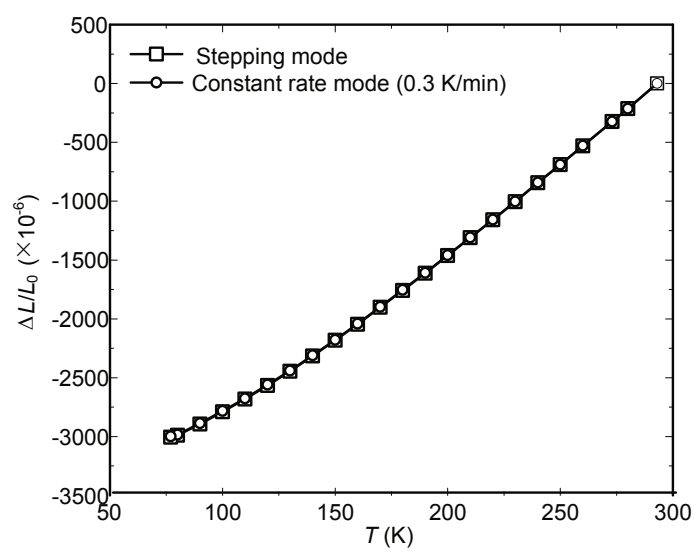

Fig. 6 Comparison of the two temperature control modes for the linear contractions of 304 stainless steel

\subsection{Correction of sensitivity coefficient of strain gage for low temperatures}

According to Eqs. (2)-(6), the measurement of $\Delta \varepsilon_{\mathrm{t}}$ is related to the sensitivity coefficient of strain gage $K_{\mathrm{s}}$. Since the sensitivity coefficient is significantly temperature-dependent (Yamaura, 1991), neglecting the variation in the sensitivity coefficient will bring errors to the measurement results for the cases of very low or very high temperatures.

To correct the sensitivity coefficient of the strain gage at low temperatures, the linear contractions of 304 stainless steel, measured in the temperature range of $293 \mathrm{~K}$ to $77 \mathrm{~K}$ with the nominal sensitivity coefficient for the room-temperature applications, were compared with the source data cited from NIST (Corruccini and Gniewek, 1961). As shown in Fig. 7, the deviation increases with the decrease of temperature, with a relative deviation of $6.92 \%$ at $80 \mathrm{~K}$. The calculated sensitivity coefficient is 1.916 at $80 \mathrm{~K}$, which has a relative deviation of $8.88 \%$ from the nominal sensitivity coefficient of 1.76 . A correction coefficient defined as the ratio of the sensitivity coefficient of the strain gages at a given temperature to that at the room-temperature is presented in Fig. 8. We can find that the correction coefficient increases with the decrease of temperature, so does the corrected sensitivity coefficient. 


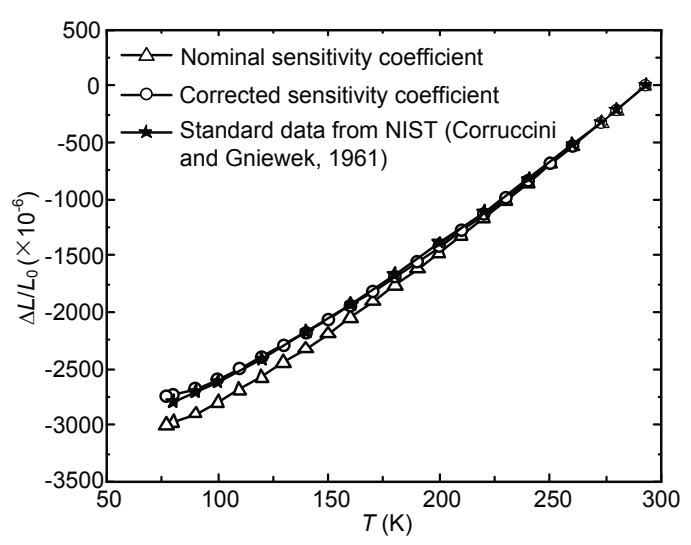

Fig. 7 Linear contractions relative to $293 \mathrm{~K}$ of 304 stainless steel in the range of 77-293 K

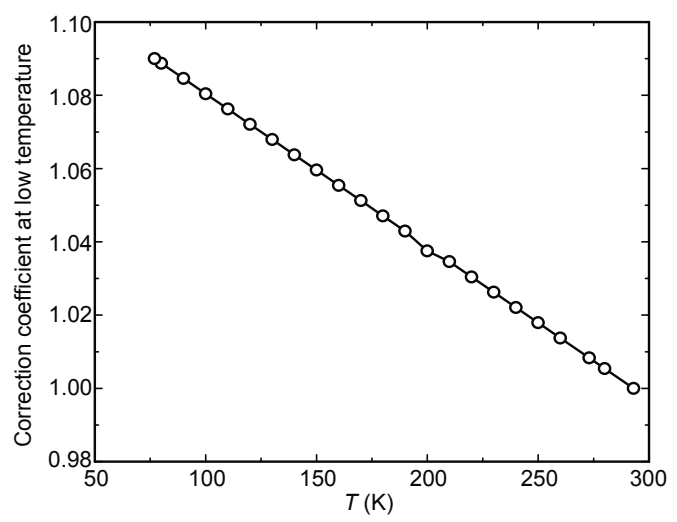

Fig. 8 Correction coefficient for the sensitivity coefficient at low temperatures

The linear contractions of 304 stainless steel with the corrected sensitivity coefficient are quite consistent to the source data from NIST (Corruccini and Gniewek, 1961), also as shown in Fig. 7. The relative deviations (absolute value) for more temperatures are given in Table 1, from which we can find that the relative deviation for the cooling-down process from $293 \mathrm{~K}$ to $80 \mathrm{~K}$ is $1.80 \%$.

\subsection{Validation of test apparatus}

To validate the test apparatus and method for the cases at low temperatures, the linear contractions of oxygen-free copper with the corrected sensitivity coefficient in the range of 77-293 K were also measured and compared with the source data from NIST (Corruccini and Gniewek, 1961), as shown in Fig. 9. The relative deviations (absolute value) for more temperatures are given in Table 2, with a rela- tive deviation of $2.37 \%$ for the cooling-down process from $293 \mathrm{~K}$ to $80 \mathrm{~K}$, which indicates that the corrected sensitivity coefficient is applicable for diverse solid materials in the temperature range of 77-293 K.

Table 1 Comparison of measured linear contractions relative to $293 \mathrm{~K}$ of 304 stainless steel in the coolingdown process from $293 \mathrm{~K}$ to $77 \mathrm{~K}$ with the source data from NIST (Corruccini and Gniewek, 1961)

\begin{tabular}{cccc}
\hline $\begin{array}{c}\text { Temperature } \\
(\mathrm{K})\end{array}$ & $\begin{array}{c}\text { Experiment } \\
\text { data }\left(\times 10^{-6}\right)\end{array}$ & $\begin{array}{c}\text { NIST data } \\
\left(\times 10^{-6}\right)\end{array}$ & $\begin{array}{c}\text { Relative } \\
\text { deviation }(\%)\end{array}$ \\
\hline $293-280$ & -212.4 & -205 & 3.62 \\
$293-273$ & -322.0 & -314 & 2.56 \\
$293-260$ & -521.5 & -514 & 1.46 \\
$293-240$ & -824.1 & -817 & 0.86 \\
$293-220$ & -1122.4 & -1110 & 1.11 \\
$293-200$ & -1405.2 & -1389 & 1.17 \\
$293-180$ & -1675.5 & -1670 & 0.33 \\
$293-160$ & -1933.8 & -1930 & 0.20 \\
$293-140$ & -2170.9 & -2180 & 0.42 \\
$293-120$ & -2387.6 & -2410 & 0.93 \\
$293-100$ & -2575.8 & -2610 & 1.31 \\
$293-90$ & -2661.0 & -2710 & 1.81 \\
$293-80$ & -2739.8 & -2790 & 1.80 \\
$293-77$ & -2750.3 & & \\
$293-70$ & & -2850 & \\
\hline
\end{tabular}

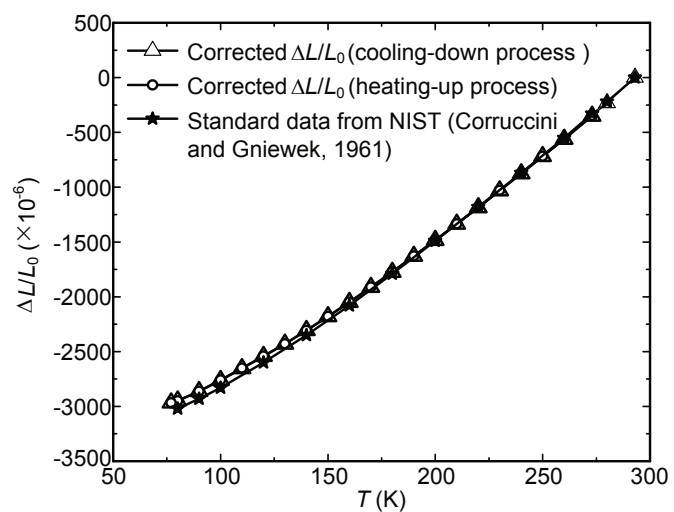

Fig. 9 Linear contractions relative to $293 \mathrm{~K}$ of oxygenfree copper in the range of $77-293 \mathrm{~K}$

Additionally, the measured linear contractions in the processes of cooling down and warming up are both shown in Fig. 9, which are highly consistent with a maximum deviation of $0.18 \%$. The consistent results for the cooling-down and warming-up processes further present the indirect proof for the success of the system in the accuracy and uniformity of controlled temperatures. The rationalities of the apparatus' thermal design and the controlled temperature 
varying rate $(0.3 \mathrm{~K} / \mathrm{min})$ are also proven. For some alloys, the thermal expansion features are different during the processes of cooling down and warming up, due to the metallographic change. The measurement system developed in this work can be applied to measure the linear contractions during both the cooling-down and warming-up processes of those alloys.

Table 2 Comparison of measured linear contractions relative to $293 \mathrm{~K}$ of oxygen-free copper in the coolingdown process from $293 \mathrm{~K}$ to $77 \mathrm{~K}$ with the source data from NIST (Corruccini and Gniewek, 1961)

\begin{tabular}{cccc}
\hline $\begin{array}{c}\text { Temperature } \\
(\mathrm{K})\end{array}$ & $\begin{array}{c}\text { Experiment } \\
\text { data }\left(\times 10^{-6}\right)\end{array}$ & $\begin{array}{c}\text { NIST data } \\
\left(\times 10^{-6}\right)\end{array}$ & $\begin{array}{c}\text { Relative } \\
\text { deviation }(\%)\end{array}$ \\
\hline $293-280$ & -232.9 & -220 & 5.85 \\
$293-273$ & -350.4 & -330 & 6.18 \\
$293-260$ & -562.1 & -550 & 2.20 \\
$293-240$ & -876.4 & -870 & 0.73 \\
$293-220$ & -1185.6 & -1180 & 0.48 \\
$293-200$ & -1485.3 & -1490 & 0.32 \\
$293-180$ & -1775.0 & -1790 & 0.84 \\
$293-160$ & -2050.9 & -2080 & 1.40 \\
$293-140$ & -2370.3 & -2350 & 1.82 \\
$293-120$ & -2541.7 & -2600 & 2.24 \\
$293-100$ & -2762.5 & -2830 & 2.38 \\
$293-90$ & -2863.4 & -2930 & 2.27 \\
$293-80$ & -2948.4 & -3020 & 2.37 \\
$293-77$ & -2968.2 & & \\
$293-70$ & & -3100 & \\
\hline
\end{tabular}

\section{Conclusions}

An experimental setup with a PID temperature control system based on the strain gage method has been developed to measure the thermal expansion of solid materials at low temperatures (77-293 K), with two temperature control modes, i.e., the stepping mode and constant rate mode. The relatively small dimensions of the test specimen can reduce the impact of the non-uniform temperature field on measurement accuracy. With a computer-aided measuring system, the setup is easy and at low cost to construct and operate.

For a quick and accurate measurement, the constant rate mode was adopted in our present work. Under the constant temperature varying rate of $0.3 \mathrm{~K} / \mathrm{min}$, accomplishing a relatively quick measurement requires $14 \mathrm{~h}$. The sensitivity coefficient of the strain gages was corrected in the temperature range of $77-293 \mathrm{~K}$, by comparing the measured thermal expansion data of 304 stainless steel with the source data from NIST. With the corrected sensitivity coefficient, the measured linear contractions of the oxygen-free copper are quite consistent to the NIST data with a relative deviation of $2.37 \%$ for the cooling-down process from $293 \mathrm{~K}$ to $80 \mathrm{~K}$, which indicates that the corrected sensitivity coefficient is applicable for the linear contraction measurement of diverse solid materials in the temperature range of 77-293 K. Additionally, the measured data in the processes of cooling down and warming up are highly consistent with a maximum deviation of $0.18 \%$, proving the rationality in the apparatus' thermal design and the controlled temperature varying rate $(0.3 \mathrm{~K} / \mathrm{min})$.

\section{References}

ASTM E228-2006. Standard Test Method for Linear Thermal Expansion of Solid Materials with a Push-rod Dilatometer. American Society for Testing Materials.

Clark, A.F., 1968. Low temperature thermal expansion of some metallic alloys. Cryogenics, 8(5):282-289.

Corruccini, R.J., Gniewek, J.J., 1961. Thermal Expansion of Technical Solids at Low Temperatures: A Compilation from the Literature. US Department of Commerce, National Bureau of Standards.

Deng, D.Q., Xu, L., 2003. Measurements of thermal expansion coefficient of phenolic foam at low temperatures. Cryogenics, 43(8):465-468. [doi:10.1016/S0011-2275(03) 00122-X]

Hannah, R.L., Reed, S.E., 1992. Strain Gage Users' Handbook. Elsevier Science Publishers Ltd., London.

James, J.D., Spittle, J.A., Brown, S.G.R., et al., 2001. A review of measurement techniques for the thermal expansion coefficient of metals and alloys at elevated temperatures. Measurement Science and Technology, 12(3):R1. [doi:10.1088/0957-0233/12/3/201]

Kaufman, A., 1963. Investigation of strain gages for use at cryogenic temperatures. Experimental Mechanics, 3(8): 177-183.

Poore, M.W., Kesterson, K.F., 1978. Measuring the thermal expansion of solids with strain gages. Journal of Testing Evaluation, 6(2):98-102.

Scalea, F.L., 1998. Compensation of thermal output of strain gages on orthotropic materials: case of one compensating gage for multiple active ones. Experimental Techniques, 22(6):30-33. [doi:10.1111/j.1747-1567.1998.tb02297.x]

Tezvergil, A., Lassila, L.V.J., Vallittu, P.K., 2003. The effect of fiber orientation on the thermal expansion coefficients of fiber-reinforced composites. Dental Materials, 19(6): 
471-477. [doi:10.1016/S0109-5641(02)00092-1]

Valentich, J., 1985. Thermal expansion of solids from $-261^{\circ} \mathrm{C}$ to $173{ }^{\circ} \mathrm{C}$ using strain gauges. Cryogenics, 25(2):63-67.

Walsh, R.P., Reed, R.P., 1994. Thermal expansion measurements of resins $(4 \mathrm{~K}-300 \mathrm{~K})$. In: Advances in Cryogenic Engineering Materials, Springer, USA, p.1145-1151.
Yamaura, Y., 1991. Measurement of strain and displacement in cryogenic environment with strain gauges. Cryogenics, 26(6):448-455 (in Japanese).

Yasmin, A., Daniel, I.M., 2004. Mechanical and thermal properties of graphite platelet/epoxy composites. Polymer, 45(24):8211-8219. [doi:10.1016/j.polymer.2004.09.054]

\section{中文概要：}

\section{本文题目：基于应变片法的低温条件下热膨胀特征参数的测量方法与装置}

Measurement of thermal expansion at low temperatures using the strain gage method

研究目的: 为了满足低温系统的材料选择和结构设计对于材料热膨胀特征参数的需求, 研发低温条件 下精确、快速、方便操作、低成本的热膨胀特征参数测量方法和系统装置。

创新要点: 完成了卡玛合金䇴应变片在 77-293 K 低温温区敏感系数的修正, 保证了基于应变片技术的 低温条件材料热膨胀特征参数测量的精度; 所研制装置合理的热设计和等速率式温度控制 模式使得材料热膨胀特征参数在 77-293 K 温区的测量可在 14 小时内快速完成。

研究方法: 针对 77-293 K 温区, 基于应变片测量方法, 研制了采用比例-积分-微分 (PID) 温控系统 的固体材料热膨胀特征参数测量装置（见图 2 和 3)。通过将 304 不锈钢的测量数据与美国 国家标准与技术研究院 (NIST) 公布数据进行比较, 完成了卡玛合金䈃应变片在 77-293 K 低温温区的敏感系数修正 (见图 7 和 8)。采用修正后的敏感系数进行无氧铜线性收缩率测 量, 并与 NIST 公布数据比较 (见图 9 和表 2), 验证了该装置在 77-293 K 低温温区的测 量精度。

重要结论：获得了 77-293 K 低温温区卡玛合金䈃应变片敏感系数的修正结果; 基于修正敏感系数的应 变片法测量装置, 采用 $0.3 \mathrm{~K} / \mathrm{min}$ 的等速率式温度控制模式, 可实现 $77-293 \mathrm{~K}$ 低温温区固 体材料热膨胀特征参数的精确、快速测量。 